\title{
Assessment of some home processes for decontamination of insecticide residues in vegetables
}

ARVIND KUMAR AYAM, ARUN SAHU, DOMAN SINGH TEKAM, CHANDRAMANI SAHU* AND V. K. KOSHTA

Department of Entomology, College of Agriculture, Indira Gandhi Agricultural University, RAIPUR (C.G.) INDIA

\section{ARITCLE INFO}

Received : 25.12 .2016

Revised : 07.03.2017

Accepted : 13.03 .2017

\section{KEY WORDS :}

Residue, Vegetable,

Home process,

Endosulfan, Tomato

*Corresponding author:

Email : chandrasahu2111@gmail.com

\begin{abstract}
The present investigation was conducted at "Residue Analysis Laboratory" Department of Entomology, College of Agriculture, Raipur (C.G.) during 2009-2010 on Assessment of insecticide residues in vegetables. The indiscriminate use of pesticide on vegetables possesses serious residue problems in humans, animals and environment. The residue is above the Maximum Residue Limit values. Contamination may occur mainly due to harvest of crops before the recommended waiting period. The household processing is the preparation of food using like washing, peeling, cooking, trimming or hulling is reduce to some extent of toxicity from food material. This present results revealed that out of different home processing procedures, tap water wash for 15 minutes was found to be the best for decontamination of endosulfan residues on tomato to an extent of 89.59 per cent followed by hot water treatment $(84.24 \%)$.
\end{abstract}

How to view point the article : Ayam, Arvind Kumar, Sahu, Arun, Tekam, Doman Singh, Sahu, Chandramani and Koshta, V.K. (2017). Assessment of some home processes for decontamination of insecticide residues in vegetables. Internat. J. Plant Protec., 10(1) : 83-86, DOI : 10.15740/ HAS/IJPP/10.1/83-86. 